\title{
O filho bastardo: o vampirismo em João Cardoso de Menezes
}

e Souza

\author{
The bastard son: vampirism in João Cardoso de Menezes e Souza \\ Letícia Cristina Alcântara RODRIGUES* \\ Universidade Federal de Goiás (UFG)
}

RESUMO: Cid Vale Ferreira (2002) afirma que o vampiro é o fruto bastardo da mescla incestuosa de Amor e Morte. Nesse sentido, encontramos no romance em forma de poema "Octavio e Branca ou a maldicção materna", de João Cardoso de Menezes e Souza, um exemplar dessa união. João Cardoso (1827-1915) apresenta uma tônica gótica em suas obras e um timbre tétrico que repercute na dicção de Álvares de Azevedo entre outros. É um dos poucos poetas brasileiros do Romantismo a trabalhar o tema do vampirismo em voga na então produção artística europeia. Seu poema "Octavio e Branca ou a maldicção materna" é, provavelmente, a primeira obra sobre vampiros da literatura brasileira. Assim, propomos um estudo da figura vampírica no poema, no sentido de compreender, por meio da hermenêutica simbólica, como esse personagem mitológico se torna filho das divindades Amor e Morte, apoiando-nos em teóricos que se detiveram no estudo do vampiro.

PALAVRAS-CHAVE: João Cardoso de Menezes e Souza. Amor. Morte. Vampirismo. Hermenêutica simbólica.

ABSTRACT: Cid Ferreira Vale (2002) claims that the vampire is an incestuous offspring, the mixture between Love and Death. With that in mind, we can see in novel in verses "Octavio e Branca ou a maldicção materna", by João Cardoso de Menezes e Souza, an example of this union. João Cardoso (1827-1915) displays a gothic tone in his works, and a gloomy register that resonates in Álvares de Azevedo's diction, among others. He is one of the few Brazilian romantic poets who works with vampirism, a theme that was then in vogue in European artistic production. His poem "Octavio e Branca ou a maldicção materna" is probably the first text about vampires in Brazilian literature. Therefore, we propose a study of the vampire character in this poem in order to understand, through symbolic hermeneutics, how this mythological character becomes a child of Love and Death. In our analysis, we rely on theoreticians who have devoted themselves to vampire studies.

KEYWORDS: João Cardoso de Menezes e Souza, Love, Death, Vampirism, Symbolic Hermeneutics.

\footnotetext{
" Doutoranda em Letras e Linguística pela Universidade Federal de Goiás (FL/UFG). E-mail: letycrys@gmail.com
} 


\section{Introdução}

O personagem vampírico está presente nas narrativas desde tempos imemoráveis. Seja no relato oral ou escrito, esse ser das trevas que habita o imaginário humano está intimamente ligado tanto a Eros quanto a Tânatos, divindades gregas que personificam o Amor e a Morte, respectivamente.

Assim, propomos no presente estudo uma análise do romance em forma de poema de João Cardoso de Menezes e Souza, intitulado "Octavio e Branca ou a maldicção materna", provavelmente a primeira obra sob o tema do vampirismo na literatura brasileira. A obra nos apresenta um novo olhar sobre essa criatura das trevas, em parte enevoada pelos versos de João Cardoso, mas também explicitada pelas próprias explicações do poeta ao final de seu trabalho.

\section{O vampirismo, Eros e Tânatos}

Nos diversos relatos que encontramos sobre o vampiro, apreendemos este ser como caracterizado como a encarnação de maus presságios ou portador de uma dualidade de forças, estigmatizado por romper barreiras e, muitas vezes, por ser subversivo em relação às convenções sociais e humanas, além de ser portador de um erotismo nato e representar um agente da morte. Conforme Marco Moraes aponta, o vampiro é "um mosaico de cores e traços surgidos de diferentes lugares que se juntaram com o tempo e moldaram, lentamente, a fisionomia que hoje temos dele: um morto que levanta da tumba para se alimentar do sangue dos vivos" (MORAES, 2003, p. 4). No entanto, não podemos rotulá-lo apenas como um sanguessuga, pois há diversos tipos de vampirismo, como os vampiros psíquicos ou emocionais e energéticos, que, conforme Nina Auerbach afirma, alimentam-se de "energia, generosidade emocional, autocontrole, criatividade, talento, memórias" (AUERBACH, 1995, p. 102, tradução nossa $\left.{ }^{1}\right)$.

Essa criatura, nascida nas lendas e relatos orais, tornou-se mais vívida nas páginas literárias, que, a partir do século XIX, tomaram-no como um dos personagens principais do gótico. Assim, encontramos no texto de João Cardoso algumas características que remetem a esse estilo literário, como a presença do castelo, a atmosfera lúgubre, a possibilidade sobrenatural e também a morte.

\footnotetext{
${ }^{1}$ No original, "energy, emotional generosity, self-control, creativity, talent, memories".
} 
Meia noite sôou! - Por toda a parte

Silencio sepulcral desdobra as azas!

Nem estrondo de andar, que trilhe as ruas

Nem brisa, que murmure brandamente!

$[\ldots]$

Era a hora em que o negro anjo da morte

Seguido d'um cortejo de finados,

Ergue co'a espada as lápides dos mortos

(SOUZA, 2002, p. 210).

Nesses versos, encontramos o tom macabro que marca a entonação do poema do escritor, trazendo a força sobrenatural para aquele mundo narrado, possibilitando a presença de elementos fantásticos e seres que não pertencem à ordem natural do mundo. Assim, a morte é invocada tanto pela atmosfera mortuária quanto pela figura do anjo negro.

Inúmeras são as obras que trazem o vampiro como personagem principal, descrevendo-o como um sugador de vidas, à procura de saciar sua sede, ou terminar algo inacabado. Sua figura, durante muito tempo, foi utilizada como um standard de qual comportamento não seguir, motivo pelo qual encontramos, na década de 1980, sua associação às doenças sexualmente transmissíveis, como a AIDS - Acquired Immune Deficiency Syndrome. Essa ligação, além do comportamento rebelde do vampiro, aquele que se insurge contra a Morte, também ocorre pela presençã do elemento erótico no mito. Desde Lâmia e Lilith, na mitologia grega e hebraica respectivamente, até nos textos que trazem o vampiro astucioso e galante - como a vampira Carmilla, de Le Fanu (1872); o noivo Guilherme em "Lenore”, de Gottifried August Bürger (1773); a noiva no poema "A noiva de Corinto", de Goethe (1797); e Lestat, de Anne Rice (1976) - a presença do erotismo é acentuada no comportamento do vampiro, que preza de sua liberdade para poder dar vazão a sua expressão sexual.

O erotismo está relacionado a Eros, o deus grego associado ao amor, que, na Teogonia, está descrito como um dos deuses primordiais existentes desde antes do universo:

Bem no início, Abismo nasceu; depois,

Terra largo-peito, de todos assento sempre estável, dos imortais que possuem o pico do Olimpo nevado, o Tártaro brumoso no recesso da terra largas-rotas e Eros, que é o mais belo entre os deuses imortais, o solta-membros, e de todos os deuses e todos os homens subjuga, no peito, espírito e decisão refletida (HESÍODO, 2013, p. 116-122) 
O poder da beleza é dado a ele, que é capaz de inspirar grandes feitos, tanto em relação aos mortais quanto aos imortais. É-lhe concedido, no texto de Hesíodo, "um poder com extensão suficiente, $[\ldots]$ para assegurar tanto a coesão como a perenidade do universo" (apud LÉVY, 2005, p. 319), pois Eros é uma força geratriz, oculta e monstruosa, uma potência cósmica que penetra o universo e o amor doce-amargo que confunde sentimentos e gera lamentos.

Conforme Junito Brandão (1986), o mito de Eros possui muitas variantes e diversificadas genealogias, como a que Platão apresenta, pela voz de Aristófanes, em $O$ banquete. Nesse diálogo, Eros é filho de Póros (Expediente) e Penía (Pobreza) e, por esse motivo, possui características bem definidas, que fazem desse deus "uma força, uma 'energia', perpetuamente insatisfeito e inquieto: uma carência sempre em busca de plenitude. Um sujeito em busca do objeto" (BRANDÃO, 1986, p. 187, grifos do autor).

O vampiro, como ser que não pertence nem a um mundo nem a outro, também pode ser entendido como uma criatura em busca de algo: seja a vingança, seja o amor perdido, seja o simples fato de querer manter-se nesse meio-termo. Compreendemos, dessa forma, o vampirismo como um contraste à santidade da criação divina, sendo, muitas vezes, uma extensão da imagem do Demônio. Assim, sua associação a Eros diz respeito ao embate entre o espírito criador e sua força destruidora, como podemos encontrar nas peças de Eurípedes, ${ }^{2}$ em que esse deus "aparece armado com um arco. Os projéteis disparados por Eros provocam dores e levam as vítimas à loucura e a atos criminosos" (SCHÜLER, 1994, p.101).

Relacionados a Eros, podemos citar os íncubos e os súcubos, seres demoníacos que atacavam jovens inocentes durante o sono. O primeiro era o demônio masculino e o segundo, o feminino, e ambos cometiam inomináveis atos sexuais com suas vítimas durante a noite. Essas criaturas podem ser associadas ao vampirismo uma vez que, após os ataques, suas vítimas sentiam-se esgotadas fisicamente, pois eles sugavam as energias humanas durante o ato sexual (IDRICEANU; BARTLETT, 2007). Segundo Flavia Idriceanu e Waine Bartlett (2007), a crença nos súcubos e íncubos esteve bastante disseminada durante os tempos medievais, sendo utilizados pela Igreja Católica como

\footnotetext{
${ }^{2}$ Segundo Lévy (2005), Eurípedes é o introdutor de Eros portando um arco e flechas, concedendo à entidade mitológica o poder de arruinar a vida daqueles a quem toca com seu amor.
} 
forma de repressão sexual, reforçando o tabu a respeito do sexo nesse período e nos posteriores.

Assim como o vampiro está ligado a Eros também podemos relacioná-lo com Tânatos, uma vez que é um ser paradoxal, está vivo e morto ao mesmo tempo. Tânatos, segundo Hesíodo, é filho de Nix, noite, e irmão gêmeo de Hipno, deus do sono, e de Moira e Quere. Ele é "o gênio masculino alado que personifica a Morte" (BRANDÃO, 1986, p. 226), sendo essa morte o "ocultar-se, ser como sombra" (1986, p. 225, grifos do autor), representando o lado perecível e destruidor da vida.

Nesse sentido, as palavras de Ferreira (2003), que trazem o vampiro como um filho bastardo ${ }^{3}$ dessas divindades, tornam-se claras, à medida que encontramos no mito vampírico tanto a força vital e inquieta de Eros quanto a sombra imposta por Tânatos, a perenidade à qual até essa criatura está presa, condicionada a viver sob certos aspectos, como a noite.

É essa dualidade que encontramos no texto de João Cardoso de Menezes e Souza, "Octavio e Branca ou a maldicção materna". Os jovens amantes, Branca e Octavio, são atingidos pelo poder criador de Eros e tomados pela perenidade de Tânatos. Impedidos pelos pais da jovem de concretizarem-se no amor, restam-lhes a morte e, sob esse aspecto, a sede de vingança contra aquele que os condenaram. Como já vimos, o vampiro, muitas vezes, foi tomado como esse ser vingativo, que retornava da tumba para punir os vivos e os condenar à morte.

\section{João Cardoso e os vampiros}

João Cardoso, poeta, político, professor, jornalista e tradutor, nasceu em Santos em 1827, frequentando posteriormente a Academia de Ciências Jurídicas e Sociais de São Paulo, onde teve contato com toda uma geração de jovens influenciados pela "rebeldia de Byron" (FERREIRA, 2003, p. 202), como Bernardo Guimarães e Álvares de Azevedo. Em 1849, publicou seu primeiro livro A harpa gemedora, "um dos sustentáculos de nossa segunda geração romântica” (FERREIRA, 2003, p. 201). Em

\footnotetext{
${ }^{3}$ Segundo Aristófanes, na obra Ornithes, Eros é filho da Noite: "No começo era o Vazio e a Noite e o negro Érebo e o vasto Tártaro; nem a terra, nem o ar, nem o céu existiam. No seio infinito do Érebo, primeiro a Noite de negras asas produziu um ovo sem germe, do qual, no curso das estações, nasceu Eros" (apud LÉVY, 2005, p. 320). Como Tânatos também é filho da Noite - Nix -, essas duas deidades Eros e Tânatos - seriam irmãs.
} 
1883, foi designado Barão de Paranapiacaba, fato este tomado por Ferreira como um dos motivos da relegação da poesia de João Cardoso, uma vez que nas entrelinhas da crítica as “incursões poéticas do 'Velho Barão' sobrepuseram-se às composições do 'João Cardoso', agregando hipocrisia e preconceito à apreciação de seu legado poemático" (FERREIRA, 2003, p. 201).

Influenciado na "primeira mocidade" (FERREIRA, 2003, p. 203) pela leitura de "Lenore", de Bürger, o poeta santista publicou a tragédia familiar "Octavio e Branca ou a maldicção materna", na qual encontramos elementos típicos da narrativa gótica medieval e também influência da atmosfera macabra e vampírica do poema de Bürger. Ainda, pelas notas de João Cardoso sobre seu poema, podemos apreender ainda a influência de Lord Ruthven, de John Polidori e, provavelmente, das inúmeras adaptações realizadas sobre esse personagem icônico da literatura.

Entretanto, é no poema "Lenore" que encontramos a maior influência, uma vez que no poema de Bürger a morte é o grande empecilho à concretização em vida do amor de Lenore e seu noivo. Na obra de João Cardoso, a família de Branca Holbachis é a responsável por esse impedimento amoroso entre a jovem e o amante Octavio, cuja origem social não era apreciada e digna da jovem dama. Assim como Lenore se indigna contra os céus pelo destino do noivo, Branca se rebela contra a família para se entregar aos braços do amante, como podemos verificar no seguinte trecho:

\footnotetext{
Só me prende dever: um pai que adóro, Cuja velhice ameigo e suaviso, De um lado me apresenta as cãas manchadas, E o coração de angustias retalhado. Negro quadro de tintas carregadas Me pinta moribunda a mãe querida Prostrada nas angustias da agonia, E a quem vou despenhar na sepultura. Pareço divisar brandões accesos Em torno de um esquife mortuario.. Mas embora, pr'a os céos alçando o vôo, Meu anjo protector de mim se aparte, Vou affrontar a maldição paterna, Pompas de nome, e opinião do mundo. Vamos, que - á tua discrição me entrego, Vamos, que quero respirar teu halito [...]. (SOUZA, 2003, p. 212)
}

Encontramos nesse trecho a angústia da jovem, dividida entre os laços familiares e o amor de Octavio, bem como sua decisão de não se ater a nomes e opiniões. Para a 
época em que é escrito o romance, assim como o período em que se passa tal história, a decisão de Branca demonstra uma força de vontade e a grandiosidade do amor sentido pelos amantes, uma vez que, ao abandonar a casa do pai, seria julgada e condenada pela sociedade, pois estaria maculada aos olhos dessa comunidade. Ao assumir essa posição, Branca invoca uma das maiores características do vampirismo, o estar à margem, o ser impuro e que rompe com as regras sociais, o pecador e imoral, condenado à exclusão.

Essa criatura é elegida pelo poeta nos primeiros versos de seu romance e retomada posteriormente pelas notas do autor, que esclarecem sobre essa criatura, dando-nos a oportunidade de contextualizá-la em sua obra. João Cardoso de Menezes e Souza apresenta duas versões sobre esse ser:

Mr. Eugenio Sue no Judeo Errante falla do Vampiro, e pinta-o como um morcêgo colossal, que espera o somno de sua victima para vir rasgar-lhe as veias, e beber-lhe o sangue, em quanto a refresca com as azas [...] e lhe opprime o coração.

Mas o Vampiro do povo - a entidade sobrenatural é o defuncto ambulante, que quebra a lousa da sepultura, e, animado d'um espírito infernal, vem peregrinar sobre a terra, para alimentar sua ephemera existencia com o sangue dos vivos. (SOUZA, 2003, p. 220-221)

Desta forma, podemos ligar a parte inicial à final do texto de João Cardoso, no sentido de identificarmos a presença vampírica tanto de Octavio quanto de Branca, agora transformados, que podem ser apontados como os responsáveis pela morte e, então, extinção da família dos Holbachis.

\section{I}

Meia noite sôou - Nos ares tremulos Funebre echôa o som do campanario De horrôr gelando o coração dos vivos! [...] E uivos de cães, quiçá correndo em cata De maligno Vampiro redivivo.

$[\ldots]$

XVI
[...]
- Lyrio que o vento derrubou na louza -
Resalta d'entre o crepe em que se involve.
Cinge-lhe a fronte alvissima grinalda
De rózas e cecens - symbolo uzado
Da innocencia, pureza e virgindade -
Ao seu lado um semblante de mancebo,
No verdor da existencia emmurchecido;
E as lettras, que na campa se gravárão
Em dois anneis entrelaçados, dizem
- Octavio e Branca, amantes desgraçados. -


$[\ldots]$

Já banqueou a lagem do sepulcro.

Apagárão-se as tóchas mortuarias,

E findarão-se os psalmos dos finados;

Apenas bruxolêa a luz mortiça

Da lampada sagrada sobre a campa,

Que encerra os novos hospedes da mórte.

[...]

Só o sussuro d'aza dos morcegos

Voando em tôrno á lampada, quebrava

Essa mudez solemne e atterradôra.

Parecia que o velho adormecera

[...]

E o sacristão abrio do templo as portas

Para resar-se a missa da alvorada,

Tropeçou sobre um corpo inanimado

(SOUZA, 2003, p. 201; p. 219-220)

Os amantes, vítimas das regras sociais de sua época, pois o matrimônio foi impedido pelo fato de Octavio não ser de nobre família, são forçados à fuga, visto que Branca já estava prometida para o rico Oranzo. A tragédia dos enamorados pode ser prevista pela atmosfera macabra dos primeiros versos, em que a noite, estática, mas opressiva, é transformada em um tabuleiro, “onde, a cada lance, anjos lúgubres convertem ressentimentos em maldições, nuvens em tempestades, e defuntos em emissários da Morte...” (FERREIRA, 2003, p. 204).

Assim, Branca e Octavio desafiam as convenções de sua época, do mesmo modo como a jovem desafiara a autoridade paterna, entregando-se, sem consentimento, ao amado. Ainda, pelo ato de rebeldia, é amaldiçoada pela mãe, tornando-se, dessa forma, vítima do anjo da morte. Esse jovem casal, tomados pela força provocadora de Eros, tem como único destino sucumbir à perenidade invocada por Tânatos.

A força que lhes deram vida e coragem para lutarem pela concretização de seu amor também pode ser considerada a causadora de sua tragédia, pois, ainda em fuga com o amado, Branca é fulminada por um raio, e Octavio, perdido no desespero, é entregue pela "rainha dos horrôres" (SOUZA, 2003, p. 218) às mãos vingativas de Oranzo, desonrado pela desfeita da jovem Holbachi.

Podemos, ainda, relacionar a morte de Branca ao próprio destino de Lenore, de Bürger, que, levada pelo noivo vivo-morto, é entregue às garras da morte após uma cavalgada infernal. Branca e Octavio tentam cavalgar o mar tempestuoso e são atingidos pelas mãos negras de Tânatos, que carrega os amantes consigo: "Misero Octavio, em vão co'as vagas luctas, / Reina a mórte - rainha dos horrôres - / Nos tremendos tufões, 
que o pego açoitão./ Ella te erruga co'as ancias d'agonia; / Sobre o negro rochêdo sobranceiro / Juncto ao corpo da amada te arremeça" (SOUZA, 2003, p. 218).

Conforma aponta Ferreira, esse poema de João Cardoso é o primeiro a trazer a temática vampírica para a literatura brasileira, pois mescla características do morcego hematófago e dos mortos-vivos europeus, "cerca de cinco décadas antes dos vôos noturnos de Drácula" (FERREIRA, 2003, p. 205), e sua criatura é fruto do amor proibido, mostrando a força devastadora que Eros possui, e que, muitas vezes, é esquecida da mitologia, pois a essa divindade é dado tanto o poder da criação quanto da destruição.

\section{REFERÊNCIAS}

AUERBACH, N. Our Vampires, Ourselves. Chicago: The University of Chicago Press, 1995.

BRANDÃO, J. de S. Mitologia grega. 18ª . ed. Petrópolis: Vozes, 1986. Vol. 1.

BÜRGER, G. A. Lenore. In: COSTA, B. (Org.). Contos clássicos de vampiros.

Tradução de Marta Chiarelli. São Paulo: Hedra, 2010. p. 215-225.

FERREIRA, C. V. Patágios fúnebres: João Cardoso e o vampirismo implícito. In: (Org.). Voivode: Estudos sobre os vampiros. Jundiaí: Pandemonium, 2003. p. 201-207.

HESÍODO. Teogonia. Tradução de Christian Werner. São Paulo: Hedra, 2013.

IDRICEANU, F.; BARTLETT, W. Lendas de Sangue: o vampiro na história e no mito. Tradução de Silvia Spada. São Paulo: Madras, 2007.

JUNG, C. G. O eu e o inconsciente. Tradução de Dora Ferreira da Silva. 21ª ed.

Petrópolis: Vozes, 2008.

LÉVY, A. Eros. In: BRUNEL, P. (Org). Dicionário de mitos literários. Tradução de Carlos Sussekind et al. Rio de Janeiro: José Olympio, 1997. p. 319-324.

MORAES, M. A. C. O vampiro: um retrato em mosaico. In: FERREIRA, C. V. (Org.). Voivode: Estudos sobre os vampiros. Jundiaí: Pandemonium, 2003. p. 3-7.

SCHÜLER, D. Narciso errante. Petrópolis: Vozes, 1994.

SOUZA, J. C. de M. Octavio e Branca ou a maldicção materna. In: FERREIRA, C. V. (Org.). Voivode: Estudos sobre os vampiros. Jundiaí: Pandemonium, 2003. p. 209-221. 